\title{
EVOLUTIONARY TRENDS AND FACIAL CONTROL OF CHITINOZOA.
}

ZASLAVSKAYA, N., Ben-Gurion University of the Negev, The Jacob Blaustein Institute for Desert Research, Ramon Science Center, Mitzpe Ramon POB 194, Israel.

Chitinozoa is an organic world group, the nature of which is not yet known. However, Chitinozoa is a uniform natural group of the organic world with a definite stratigraphical position (O-D). I suggest to use solely peridermal structures to specify evolutional trends of Chitinozoa.

1. The change of carinae that forms the morphological succession Cyathochitina calix-C. campanulaeformis-C. kuckersiana. This succession of species encompasses the early-middle Ordovician interval.

2. The change in the structure of longitudinal ridges that features the evolutionary succession Hercochitina repsinata-H. lindsaensis- $H$. crickmay at the middle-late Ordovician interval of the south part of Ontario.

3. The change in the ultrastructure of peridermal tissue. It shows well through the structure of appendices in the succession Ancyrochitina ancyrea-A. alveolata- $A$. siberica, llandovery-wenlock of the Siberian platform and ludlowpridoli of Europe and North America.

The points of peridermal appendix structure might be used for facial analysis. So, basal appendices change from simple branchwise up to complex anastomosis and loop-like during the change of the surrounding from shallowwater shelf up to a deep-water one, forming the morphology succession Ancyrochitina-Clathrochitina. Thus, evolutional trends of Chitinozoa and facial analysis might be based on a detailed study of peridermal structure morphology. 